\title{
Peningkatan Kualitas Minyak Nilam (Pogostemon Cablin Benth) menggunakan Kombinasi Metode Fermentasi, Delignifikasi dan Destilasi
}

\section{Quality Improvement of Nilam Oil (Pogostemon cablin Benth) using Combination Methode of Fermentation, Delignification and Distillation}

\author{
Salih Muharam, Lela Mukmilah Yuningsih, Iim Sulaeman Rohana \\ Program Studi Kimia, Fakultas Sains dan Teknologi, Universitas Muhammadiyah Sukabumi, \\ J1. R. Syamsudin. SH. No. 50 Kota Sukabumi, 43113, Indonesia. \\ Email: salih.ummi@gmail.com
}

Received: August 2017; Revised: August 2017; Accepted: November 2017; Available Online: November 2017

\begin{abstract}
Abstrak
Penyulingan minyak nilam tradisional dilakukan dalam kapasitas kecil dan menggunakanmetode penyulingan sederhanaberdasarkan pada perbedaan titik didih yang jauh atau salah satu komponen bersifat volatil. Proses ini menghasilkan kualitas minyak nilam kurang baik seperti bilangan asam lebih dari 8, minyak berwarna gelap, patchouli alkohol kurang dari 30\%, dan kadarair tinggi.Pada penelitian ini telah dilakukan penyulingan minyak dari tanaman nilam menggunakan kombinasi metode yaitu fermentasi-delignifikasi, destilasi dan pemurnian untuk meningkatkan kualitas minyak nilam. Hasil penelitian ini menunjukan bahwa kombinasi proses fermentasi-delignifikasi-destilasi-adsorpsi menghasilkan kualitas minyak nilam yang lebih baik dengan kualitas bilangan asam, kandungan patchouli alkohol, kadar air dan bobot jenis berturut-turut adalah 7.48, 35.60\%, $0.56 \%, 0.0957$.
\end{abstract}

Kata kunci:Minyak nilam, fermentasi, delignifikasi, destilasi, adsorpsi.

\begin{abstract}
The traditional distillation of patchouli oil conducted in small capacity and using a simple distillation method based on differences of wide a boiling point or one component is volatile. This process results a poor quality of patchouli oils such as the acid numbers is more than 8 , dark-colored oils, patchouli alcohols content is less than $30 \%$, and high water content. In this research has been done oil distillation from patchouli plants using a combination of methods i.e. fermentation-delignification, distillation and purification to improve of patchouli oil quality. The results show that the combination of the fermentation-delignification-distillation-adsorption is better in quality of patchouli oil with the acid number, patchouli alcohol content, water content and density were 7.48, $35.60 \%, 0.56 \%$, and 0.0957 respectively.
\end{abstract}

Keywords :Patchouli oil, fermentation, delignification, distillation, adsorption.

DOI: http://dx.doi.org/10.15408/jkv.v3i2.5219

\section{PENDAHULUAN}

Penyulingan minyak nilam di Indonesia banyak dilakukan dengan cara destilasi sederhana dan kapasitas kecil, proses tersebut menghasilkan kualitas minyak nilam yang kurang baik dan optimal (Alam 2007), oleh karena itu diperlukan metode pra penyulingan, penyulingan dan pemurnian yang baik untuk meningkatkan kualitas minyak nilam yang memenuhi Standar Nasional Indonesia (SNI) yaitu mengadung patchouli alkohol minimal 
$30 \%$, bilangan asam maksimal 8, berwarna kuning muda sampai coklat kemerahan.

Setya et al., (2012) telah melaporkan minyak nilam dengan kandungan Patchouli alkohol yang tinggi dapat diperoleh dari daun nilam utuh yang dicacah terlebih dahulu. Kemudian Nasruddin et al., (2009) telah melaporkan bahwa minyak nilam yang berkualitas dapat diperoleh melalui proses fermentasi dan delignifikasi daun nilam menggunakan kapang Trichoderma viride dan penambahan bahan kimia $\mathrm{NaOH}$ yang selanjutnya disuling. Kapang Trichoderma viride berperan dalam mendegradasi lignin dan hemiselulosa serta membuka struktur kristalin selulosa, sehingga pada proses penyulingan, minyak lebih mudah keluar. Peran yang sama juga ditunjukan olehlarutan $\mathrm{NaOH}$ yaitu menghilangkan senyawa lignin dari matrik tanaman nilam, sehingga proses penguapan minyak nilam akan lebih cepat terpisah dan rendemennya tinggi.

Harunsyah (2011) melaporkan proses pemurnian minyak atsiri secara fisika dapat menggunakan menggunakan adsorben tertentu seperti bentonit, arang aktif dan zeolite dan Setyaningtyas (2005) melaporkan bahwa abu sekam padi dapat digunakan sebagai adsorben karena mempunyai mempunyai kandungan karbon yang tinggidan cocok dijadikan sebagai adsorben (Saniyyah dan Nurhasni, 2010).

Pada penelitian ini telah dilakukan kombinasi metode delignifikasi, fermentasi, destilasi, adsorpsi untuk memperoleh minyak nilam yang memenuhi SNI.

\section{METODE PENELITIAN}

\section{Alat dan Bahan}

Alat-alat yang digunakan pada penelitian ini adalah; satu set peralatan alat destilasi (Gambar 1), fermentor, $\mathrm{pH}$ meter, GCMS Shimadzu-Qp 5050 dengan detektor MS-EI dan kolom DBS-MSI, fase gerak gas Helium, laju alir $2 \mathrm{~mL} / \mathrm{min}$, tekanan $80.2 \mathrm{kPa}$.

Bahan-bahan yang digunakan pada penelitian ini adalah tanaman nilam, $\mathrm{NaOH}$, kapang Trichodermaengan dengan merek dagang Trichor-M, aquadest $\mathrm{pH} 9$, zeolit 200 mesh, abu sekam padi, fenolptalein, $\mathrm{KOH}$, dan etanol $90 \%$.

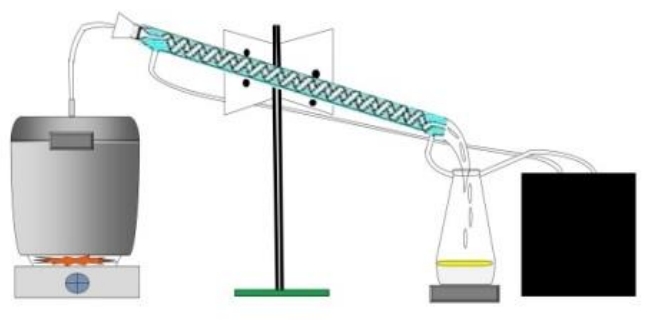

Gambar 1. Skema alat destilasi

\section{Destilasi Langsung}

3000 gram tanaman nilam kering ditimbang dan dicacah dengan ukuran $\pm 2 \mathrm{~cm}$, kemudian didestilasi dengan air pada $\mathrm{pH} 9$ suhu $100 \pm 2{ }^{\circ} \mathrm{C}$ selama 6 jam destilat minyak dipisahkan dari air menggunakan labu ekstraksi (Habibi et al., 2013). Minyak yang dihasilkan selanjutnya dianalisa warna, bobot jenis, kadar air, bilangan asam, kelarutan dalam etanol $90 \%$ serta dinalisis GCMS untuk menunjukan komposisi kimia dan kadar patchouli alkohol.

\section{Delignifikasi - Destilasi}

3000 gram tanaman berukuran $\pm 2 \mathrm{~cm}$, dilarutkan kedalam larutan $\mathrm{NaOH} \quad 0.25 \%$ dengan rasio (1000:1) pada suhu $55{ }^{\circ} \mathrm{C}$ selama 30 menit sampai larutan berwarna coklat kehitaman.Minyak yang dihasilkan selanjutnya dianalisa warna, bobot jenis, kadar air, bilangan asam, kelarutan dalam etanol $90 \%$ serta dinalisis GCMS untuk menunjukan komposisi kimia dan kadar patchouli alkohol.

\section{Fermentasi - Destilasi}

3000 gram tanaman nilam berukuran \pm 2 $\mathrm{cm}$ difermentasi dengan campuran kapang Trichoderma viride dengan air (300:60) selama 6 hari (Nasruddin et al., 2009). Minyak yang dihasilkan selanjutnya dianalisa warna, bobot jenis, kadar air, bilangan asam, kelarutan dalam etanol 90\% serta dinalisis GCMS untuk menunjukan komposisi kimia dan kadar patchouli alkohol.

\section{Fermentasi - Delignifikasi - Destilasi}

4000 gram tanaman nilam berukuran \pm 2

$\mathrm{cm}$ di fermentasi dan di delignifikasi menggunakan kapang Trichoderma viride dan larutan $\mathrm{NaOH} 0.25 \%$. Minyak yang dihasilkan selanjutnya dianalisa warna, bobot jenis, kadar air, bilangan asam, kelarutan dalam etanol 
90\% serta dinalisis GCMS untuk menunjukan komposisi kimia dan kadar patchouli alkohol.

\section{HASIL DAN PEMBAHASAN}

Tabel 1 menyajikan kualitas minyak nilam hasil destilasi langsung, delignifikasidestilasi, fermentasi-destilasi dan kombinasi fermentasi-delignifikasi-destilasi. Pada keseluruhan proses destilasi yang dilakukan, warna minyak nilam yang dihasilkan berwarna kuning muda sesuai persyaratan yang diatur dalam SNI. Yanyan et al., (2004) melaporkan minyak nilam dengan warna kuning jernih memiliki kualitas yang baik serta memiliki kadar patchuoli alkohol yang lebih tinggi.

Minyak nilam hasil destilasi langsung menghasilkan jumlah terbanyak dibandingkan dengan hasil proses destilasi kombinasi lainnya yaitu 36.55 gram, sedangkan proses kombinasi lainnya mengalami penyusutan selama proses destilasi sehingga menghasilkan jumlah minyak lebih sedikit, seperti proses delignifikasi-destilasi, fermentasi-destilasi dan fermentasi-delignifikasi-destilasi berturut-turut menghasilkan minyak 28.60 gram, 30.10 gram, 27,20 gram. Pengeringan nilam yang kurang tepat dapat mempengaruhi minyak nilam yang didapatkan (Zuliansyah et al., 2013).

Bobot jenis minyak nilam menurut SNI (2006) berkisar antara 0.950-0.957 bobot jenis minyak nilam dari seluruh proses destilasi yang dihasilkan yaitu berkisar 0.9560.957dengan demikian telah memenuhi persyaratan dan mempunyai kemurnian minyak nilam. Bobot jenis minyak nilam merupakan kriteria yang cukup penting dalam menentukan kemurnian senyawa organik (Harimurti et al., 2012).

Kadar air yang paling kecil yaitu pada proses detilasi langsung disebabkan prapenyulingan bahan baku tidak kontak langsung dengan air sedangakan proses kombinasi lainnya bahan baku kontak dengan air. Semakin kecil kadar air maka kualitas minyak semakin baik. Rendahnya kadar air menghambat pembentukan asam lemak bebas, sehingga potensi kerusakn minyak menjadi rendah, keseluruhan proses berkadar air rendah, karenatoleransi kadar air pada nilam maksimal sampai 14\% (Kataren, 1986).

Kelarutan minyak nilam dalam etanol $90 \%$, minyak dari keseluruhan proses menghasilkan larutan jernih dalam perbandingan 1:9. Harimurti et al., (2012) melaporkan bahwa semakin kecil kelarutan minyak nilam dalam etanol 90\% maka kualitas minyak nilam semakin baik. Kenaikan bilangan asam akan mempengaruhi kualitas minyak nilam, Senyawa-senyawa asam tersebut akan mengubah aroma khas dari minyak nilam. Ketika minyak nilam kontak dengan udara atau berada pada kondisi yang lembab akan mengalami reaksi oksidasi dikatalisi oleh cahaya sehingga akan membentuk suatu senyawa asam. Oksidasi komponen-komponen minyak nilam terutama dari golongan aldehid dapat membentuk gugus asam karboksilat oleh sebab itu bilangan asam akan meningkat. Kenaikan bilangan asam dipengaruhi oleh suhu tinggi pada saat penyulingan dimana kecenderungan proses oksidasi terjadi sangat besar (Harimurti et al., 2012). Tingginya bilangan asam diduga karena adanya reaksi hidrolisis (Dalimunthe et al., 2015).

Bilangan asam menurut SNI (2006) maksimal 8, bilangan asam hasil keseluruhan proses destilasi lebih dari 8. Hal itu menandakan rendahnya kualitas minyak nilam. Sehingga dilakukan proses adsorpsi dengan menggunakan abu sekam padi-zeolit. Zeolit adalah mineral kristal alumina silika tetrahidrat berpori yang mempunyai struktur kerangka tiga dimensi (Lestari, 2010). Zeolit memiliki pori dan bersifat polar yang dapat menyerap asam lemak bebas yang mempunyai gugus karboksil dengan sifat polar juga sehingga terjadi tarik menarik antara zeolit dan asam lemak bebas dari minyak nilam sehingga meurunkan bilangan asam pada minyak tersebut,dengan begitu dapat meningkatkan mutu minyak nilam. Abu sekam padi merupakan material berpori juga mempunyai gugus aktif yaitu $\mathrm{Si}-\mathrm{O}-\mathrm{Si}$ dan $\mathrm{Si}-\mathrm{OH}$ yang cocok dijadikan adsorben (Saniyyah dan Nurhasni, 2010). Bilangan asam minyak nilam menggunakan adsorben abu sekam padi-zeolit yang telah diaktivasimenghasilkan persen penurunan bilangan asam berkisar $10-15 \%$ yaitu mencapai 7.48 untuk proses kombinasi fermentasi-delignifikasi-destilasi.

Guenther, (1949) melaporkan bahwa komponen kimia penyusun minyak nilam terdiri dari dua golongan yaitu: golongan hidrokarbon yang berupa senyawa seskuiterpen, berjumlah sekitar $40-45 \%$ dari berat minyak dan golongan hidrokarbon beroksigen (oxygenated hydrocarbon) yang berjumlah sekitar $52-57 \%$ dari berat minyak. 
Patchouli alkohol merupakan komponen golongan hidrokarbon beroksigen, merupakan senyawa yang menentukan bau minyak nilam dan merupakan komponen yang terbesar di dalam minyak nilam (Trifilieff, 1980). Oleh sebab itu patchouli alcohol merupakan indikator penentuan kualitas minyak nilam

Patchuoli alkohol minyak nilam hasil keseluruhan proses destilasi memenuhi persyaratan SNI, yaitu lebih dari 30\%. Persen peak patchuoli alkohol tertinggi diperoleh pada proses fermentasi destilasi yang ditunjukan pada gambar 2. Gambar menunjukan kromatogram peak patchouli alkohol senyawa komponen yang utama dari minyak nilam dari berbagai proses diantaranya destilasi langsung, delignifikasi-destilasi, fermentasi-destilasi dan fermentasi-delignifikasi-destilasi.

Tabel 1. Kualitas minyak nilam hasil destilasi langsung, delignifikasi-destilasi, fermentasi-destilasi, delignifikasi-fermentasi-destilasi.

\begin{tabular}{|c|c|c|c|c|c|c|}
\hline No & Jenis Uji & $\begin{array}{l}\text { Persyaratan } \\
\text { SNI }\end{array}$ & $\begin{array}{c}\text { Destilasi } \\
\text { Langsung }\end{array}$ & $\begin{array}{c}\text { Delignifikasi } \\
\text {-destilasi }\end{array}$ & $\begin{array}{c}\text { Fermentasi- } \\
\text { destilasi }\end{array}$ & $\begin{array}{c}\text { Fermentasi- } \\
\text { delignifikasi- } \\
\text { destilasi }\end{array}$ \\
\hline 1 & Warna & $\begin{array}{c}\text { Kuning muda- } \\
\text { coklat } \\
\text { kemerahan }\end{array}$ & Kuning muda & Kuning muda & $\begin{array}{l}\text { Kuning } \\
\text { muda }\end{array}$ & Kuning muda \\
\hline 2 & Bobot jenis & $0.950-0.957$ & 0.956 & 0.957 & 0.957 & 0.957 \\
\hline 3 & Kadar air & & $0.198 \%$ & $0.318 \%$ & $0.358 \%$ & $0.56 \%$ \\
\hline 4 & $\begin{array}{l}\text { Kelarutan dalam } \\
\text { etanol } 90 \%\end{array}$ & $\begin{array}{c}\text { dalam } \\
\text { perbandingan } \\
1: 10\end{array}$ & $1: 9$ & $1: 9$ & $1: 9$ & $1: 9$ \\
\hline 5 & Bilangan asam & Maks. 8 & 10.68 & 9.57 & 11.73 & 8.68 \\
\hline 6 & $\begin{array}{l}\text { Bilangan asam } \\
\text { setelah adsorpsi } \\
\text { dengan abu } \\
\text { sekam padi- } \\
\text { zeolit }\end{array}$ & - & 9.68 & 8.07 & 10.96 & 7.48 \\
\hline
\end{tabular}
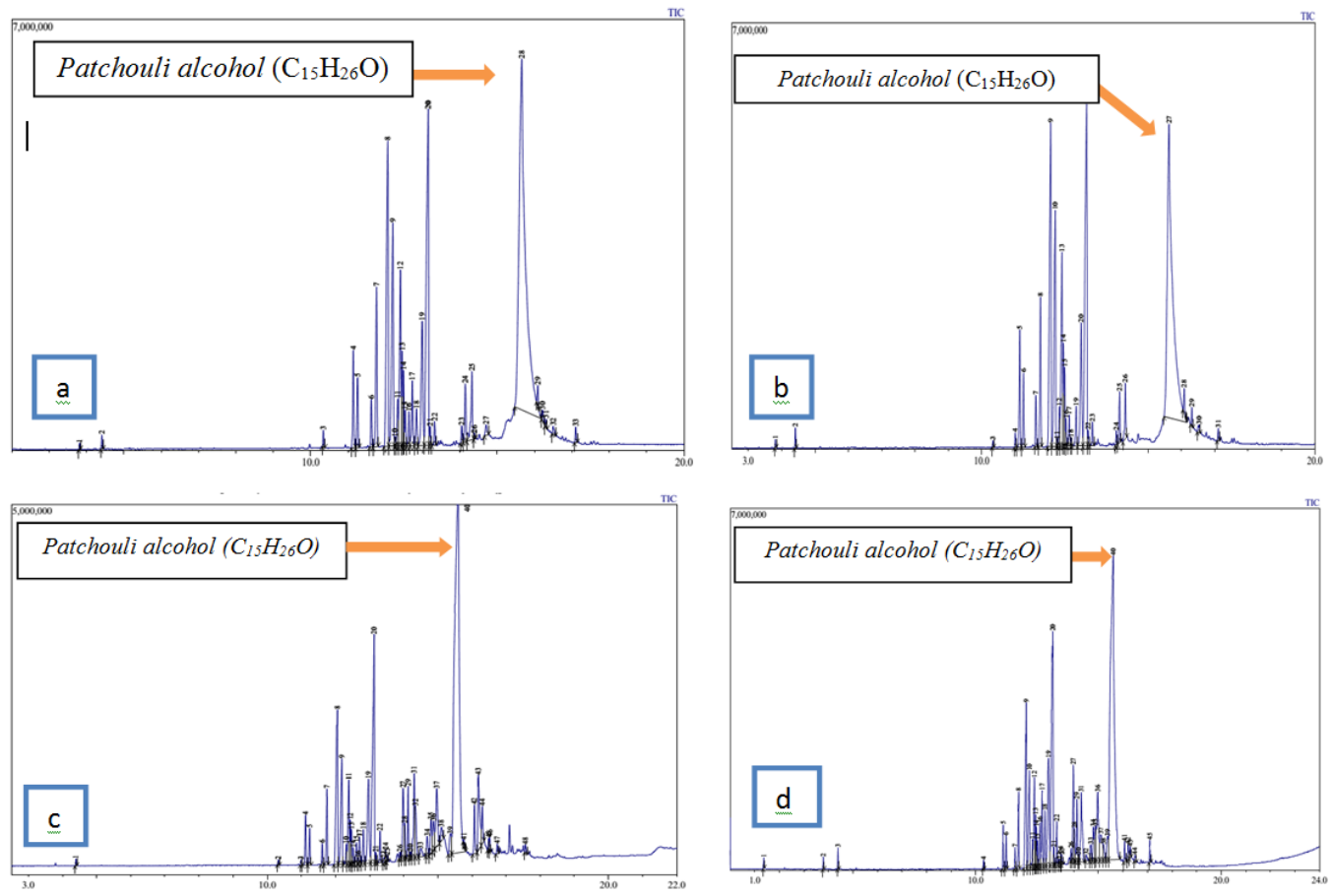

Gambar 2. Kromatogram minyak nilam hasil a) destilasi langsung, b) delignifikasi-destilasi c) fermentasidestilasi d) fermentasi-delignifikasi-destilasi. 
Hasil analisis GCMS minyak nilam hasil destilasi langsung, delignifikasi-destilasi, fermentasi-destilasi, fermentasi-delignifikasidestilasi terdapat senyawa patchouli alkohol $\left(\mathrm{C}_{15} \mathrm{H}_{26} \mathrm{O}\right)$ yang memenuhi SNI berturut-turut yaitu $39.86 \%, 34.87 \%, 39.94 \%, 35.60 \%$. Keempat data hasil GCMS tersebut menunjukan bahwa patchouli alkohol $\left(\mathrm{C}_{15} \mathrm{H}_{26} \mathrm{O}\right)$ merupakan senyawa utama yang terkandung dalam minyak nilam. Senyawa patchouli alkohol dengan persen area peak tertinggi sebesar $39.94 \%$ merupakan hasil dari proses fermentasi-destilasi.

Pada proses ini, daun nilam difermentasi dengan menggunakan kapang Trichoderma viride sebagai katalis. Trichoderma viride merupakan salah satu jenis kapang tanah yang aktif dalam melakukan dekomposisi lignoselululosa, kapang ini dapat menghasilkan enzim selulase yang mempunyai kemampuan cukup tinggi untuk memutuskan ikatan glikosidik $\beta(1,4)$ pada selulosa sehingga struktur kristalin daun nilam menjadi lebih terbuka dan minyak yang berada di dalam vakuola daun nilam dapat mudah diisolasi dengan destilasi (Nasruddin et al.,2009). Penambahan $\mathrm{NaOH}$ setelah fermentasi membantu memutuskan ikatan selulosa dan memecah vacuola tanaman nilam, melepaskan senyawa lignin yang berada pada dinding sel kedua pada lamella tengah. Menurut Brown (1983) tidak adanya lignin pada dinding sel akan mempercepat kinerja uap panas pada saat proses destilasi untuk mencapai titik dingin (slowest heating zone) sehingga mempercepat keluarnya minyak nilam, dengan demikian rendemen dan kualitas minyak nilam akan lebih meningkat (Nasrudinet al., 2009).

\section{SIMPULAN}

Metode kombinasi proses fermentasidelignifikasi-destilasi-adsorpsi menghasilkan kualitas minyak nilam lebih baik. Kualitas minyak nilam yang dihasilkan mempunyai karakteristik bilangan asam 7.48, Patchouli alkohol $35.60 \%$, kadar air $0.56 \%$, bobot jenis 0.0957 , dengan demikian kimia minyak nilam yang diperoleh telah memenuhi Standar Nasional Indonesia.

\section{UCAPAN TERIMAKASIH}

Pada kesempatan ini penulis mengucapkan terimakasih kepada PT. Djasula Wangi yang telah membantu memberikan bahan baku tanaman nilam dan program studi kimia Universitas Muhammadiyah Sukabumi yang telah memberikan fasilitas laboratorium penelitian serta staf yang turut membantu atas penyelesaian penelitian ini.

\section{DAFTAR PUSTAKA}

Alam PN. 2007. Aplikasi proses pengkelatan untuk peningkatan mutu minyak nilam Aceh. Jurnal Rekayasa Kimia dan Lingkungan. 6(2): 63-66.

Brown DE. 1983. Lignocellulose Hydrolysis.Phil (US): Trans. R. Soc. Lan.

Dalimunthe H, Harahap LA, Munir AP. 2015. Uji pengaruh suhu uap pada alat penyulingan minyak atsiri tipe uap langsung terhadap mutu dan rendemen minyak nilam. Jurnal Rekayasa Pangan dan Pertanian. 3(3): 377-381.

Guenther E. 1949. Essential Oils. Volume II. New York (US): Van Nostrand Reinhold Company.

Habibi W, Haq AZ, Prihatini P, Mahfud M. 2013. Perbandingan metode steam distillation dan steam-hydro distillation dengan microwave terhadap jumlah rendemen serta mutu minyak daun cengkeh (Syzygium aromaticum). Jurnal Teknik ITS. 2(2): F-234-F-238.

Harunsyah. 2011. Peningkatan mutu minyak nilam rakyat melalui proses pemurnian. Jurnal Teknologi. 11(1): 1-7.

Harimurti N, Soerawidjaja TH, Sumangat D, Risfaheri R. 2013. Ekstrksi minyak nilam (Pogostemon cablin Benth) dengan teknik hidrodifusi pada tekanan 1-3 bar.Jurnal Pascapanen Pertanian. 9(1): 1-10.

Hernawati NS, Budiarti A, Mahfud M. 2012. Proses pengambilan minyak atsiri dari daun nilam dengan pemanfaatan gelombang mikro (microwave). Jurnal Teknik ITS. 1(1): 1-5.

Ketaren S. 1986. Pengantar Teknologi Minyak Atsiri. Jakarta (ID): Balai Pustaka. 
Lestari YD. 2010. Kajian Modifikasi dan Karakterisasi Zeolit Alam dari Berbagai Negara. Jurusan Pendidikan Kimia. Universitas Negeri Yogyakarta. Prosiding Seminar Nasional Kimia dan Pendidikan Kimia.

Nasruddin PG, Basuni H. 2009. Pengaruh delignifikasi daun nilam (Pogostemon cablin Benth) dengan larutan naoh dan fermentasi dengan kapang trichoderma viride terhadap minyak hasil penyulingan. Jurnal Riset Industri. 3(2): 94-102.

Saniyyah N, Nurhasni H. 2010.Penyerapan Logam Ion $\mathrm{Cd}$ dan $\mathrm{Cr}$ dalam Air Limbah menggunakan Sekam Padi. Jakarta (ID): UIN Syarif Hidayatullah.

Setyaningtyas T, Zusfahair Suyata. 2005. Pemanfaatan abu sekam padi sebagai adsorben kadmium (II) dalam pelarut air.
Majalah Kimia Universitas Jenderal Soedirman. 31(1): 33-41.

SNI. 2006. Minyak Nilam. Jakarta (ID): Dewan Satandarisasi Nasional.

Trifilieff E. 1980. Isolation of the postulated precursor of nor-patchoulenol in patchouli leaves. J. Phytochemistry. 19(11): 331332.

Yanyan FN, Zainuddin A, Sumiarsa D. 2004. Peningkatan kadar patchouli alkohol dalam minyak nilam (patchouli oil) dan usaha derivatisasi komponen minornya. Jurnal Perkembangan Teknologi TRO. 16(2): 72-78.

Zuliansyah H, Sumarlan SH. 2013. Uji performa penyulingan tanaman nilam (Pogostemon cablin Benth) menggunakan boiler di kabupaten Blitar. Jurnal Bioproses Komoditas Tropis. 1(1): 62-72. 